Int. J. Dev. Biol. 59: 109-117 (2015)

doi: $10.1387 / \mathrm{ijdb} .150057 \mathrm{mp}$

\title{
AMBRA1-regulated autophagy in vertebrate development
}

\author{
MANUELA ANTONIOLI',2, FEDERICA ALBIERO ${ }^{1}$, GIAN MARÍA FIMIA ${ }^{1,3}$ and MAURO PIACENTINI ${ }^{*, 1,2}$ \\ ${ }^{1}$ National Institute for Infectious Diseases I.R.C.C.S. 'Lazzaro Spallanzani' Rome, \\ ${ }^{2}$ Department of Biology, University of Rome 'Tor Vergata', Rome, and ${ }^{3}$ Department of Biological and Environmental \\ Sciences and Technologies (DiSTeBA), University of Salento, Lecce, Italy
}

\begin{abstract}
Autophagy is a catabolic process that mediates the lysosomal turn over of organelles and macromolecules, and is strongly activated in stress conditions to ensure cell survival.Autophagy core genes are highly conserved from yeast to mammals, with an increasing number of positive and negative regulators that have evolved in higher eukaryotes. Autophagy takes part in different stages of development, as revealed by alterations in cell proliferation, differentiation and survival during the embryogenesis of organisms carrying mutations in autophagy genes. These defects are ascribed to the ability of autophagy to provide elements for new synthesis or energy production in limiting conditions during embryogenesis, as well as to contribute to the profound cell remodeling that occurs during differentiation. However, many differences have been observed in the phenotypes of autophagy mutant organisms, indicating that these genes have acquired specific functions in particular tissues, which may reflect the ability of autophagy to crosstalk with the main developmental processes. In this review, we discuss the role of upstream regulators of autophagy in the development of different model systems, focusing, in particular, on AMBRA1 (autophagy/beclin-1 regulator-1) and its role in the central nervous system.
\end{abstract}

KEY WORDS: AMBRA1, autophagy, BECLIN1, LC3, ULK

\section{Introduction}

Autophagy is a catabolic process that contributes to maintain cellular homeostasis and energy production, ensuring the turnover of macromolecules and organelles. This pathway is dramatically activated in response to metabolic stresses, such as nutrient deprivation, to supply cells with amino acids, sugar and fatty acids obtained from degradation, thus maintaining metabolism and ATP levels (Parzych and Klionsky, 2014). Moreover, autophagy contributes to organism defensive mechanisms by playing a role in different aspects of immunity, including the elimination of invasive microbes, innate immune activation and antigen presentation (Kim and Lee, 2014). A main indication of the important role of autophagy in cell maintenance is the fact that its dysfunction is linked to the development of several human diseases, including neurodegeneration, tumorigenesis, cardiovascular disorders and immune pathologies (Schneider and Cuervo, 2014).

Three main autophagic pathways have been described: microautophagy, chaperone-mediated autophagy (CMA) and macroautophagy. The main difference between them is the modality by which materials to degrade are delivered to lysosomes (Shen and Mizushima, 2014). In microautophagy, cytosolic components are directly sequestrated by lysosome through invaginations of the endosomal compartment (Li et al., 2012). In CMA, only proteins containing a specific pentapeptide motif are recognized by cytoplasmic chaperones to be unfolded and then directly translocated into the lysosome (Cuervo, 2010). In macroautophagy (hereafter referred as autophagy) unshaped vesicles, called phagophores, elongate to enwrap the cellular components to be degraded, and close to form autophagosome, the distinctive double-membrane vesicles of this process. The autophagosome slides along cytoskeletal structures to fuse first with endosomal structures to form multivesicular bodies and eventually with lysosomes to acquire a large series of hydrolytic enzymes (Klionsky et al., 2012).

The molecular components of autophagy machinery were initially identified in $S$. cerevisiae and named autophagy-related genes (ATG). To date, many of yeast orthologues have been identified in different organisms, from nematodes to mammals

\footnotetext{
Abbreviations used in this paper: AMBRA1, activating molecule in BECN1-regulated autophagy protein 1; ATG, autophagy-related genes; CNS, central nervous system; CMA, chaperone-mediated autophagy; dpf, days post-fertilization; IFN $\gamma$, interferon gamma; IL-1, interleukin 1; LAP, LC3-associated phagocytosis; LIR, LC3interacting region; LPS, lipopolysaccharide; PI3P, phosphatidylinositol-3 phosphate.
}

*Address correspondence to: Mauro Piacentini. Department of Biology, University of Rome 'Tor Vergata', Via della Ricerca Scientifica, 00133 Rome, Italy. Tel: +39-06-7259-4234. E-mail: mauro.piacentini@uniroma2.it

Accepted: 6 May 2015.

ISSN: Online 1696-3547, Print 0214-6282 
(Huang and Klionsky, 2002). ATG genes are mainly involved in the formation of autophagosomes, which include the nucleation of a pre-autophagosomal membrane structure, its elongation and the complete maturation into a closed vesicle. The nucleation is orchestrated by ULK1 (Unc-51 Like Autophagy Activating Kinase 1 ), the mammalian homologue of Atg1, and BECLIN 1 / VPS34 (Phosphoinositide-3-Kinase, Class 3) complexes together with WIPI2 (WD repeat domain, phosphoinositide interacting 2), while two conserved systems, Atg12-Atg5-Atg16 and Atg8 (LC3), allow the elongation and the maturation of autophagosomes (Fig. 1) (Klionsky et al., 2012). Various forms of so-called non-canonical autophagy, which do not require one of more of these ATG factors, have been described (Dupont and Codogno, 2013).

A complex crosstalk between autophagy and a variety of other cellular processes, including proliferation, differentiation and apoptosis, has emerged in the last decade. These studies have also contributed to elucidate how multiple signalling pathways converge to the autophagy machinery to regulate autophagy. Moreover, it has become evident that many upstream autophagy regulatory genes have evolved multiple functions, those allow to coordinate and integrate autophagy with these processes. An interesting example of this complexity comes from embryogenesis, where the contribution of different autophagy genes appears to be much variegated, as demonstrated by the different phenotypes observed upon autophagy gene mutations (Cecconi and Levine, 2008; Wada et al., 2014). In this review, we discuss the role played by autophagy in the development, focusing in particular on AMBRA1 (autophagy/beclin-1 regulator 1), a protein that regulates different steps of the autophagic process by acting as a crucial nodal point in the crosstalk of multiple signalling pathways with autophagy.

\section{LC3 (light chain 3) complex and embryogenesis}

Two ubiquitin-like conjugation systems are essential for the formation of autophagosomes (Fig. 1). In the first system, Atg7 activates Atg12 that is transferred to Atg10 and then conjugated to Atg5 (Mizushima et al., 1998). Subsequently, the Atg12-Atg5 complex non-covalently binds Atg16L1 allowing their assembly in tetramers (Mizushima and Kuma, 2003). The second ubiquitin-like system involves the microtubule-associated protein light chain 3

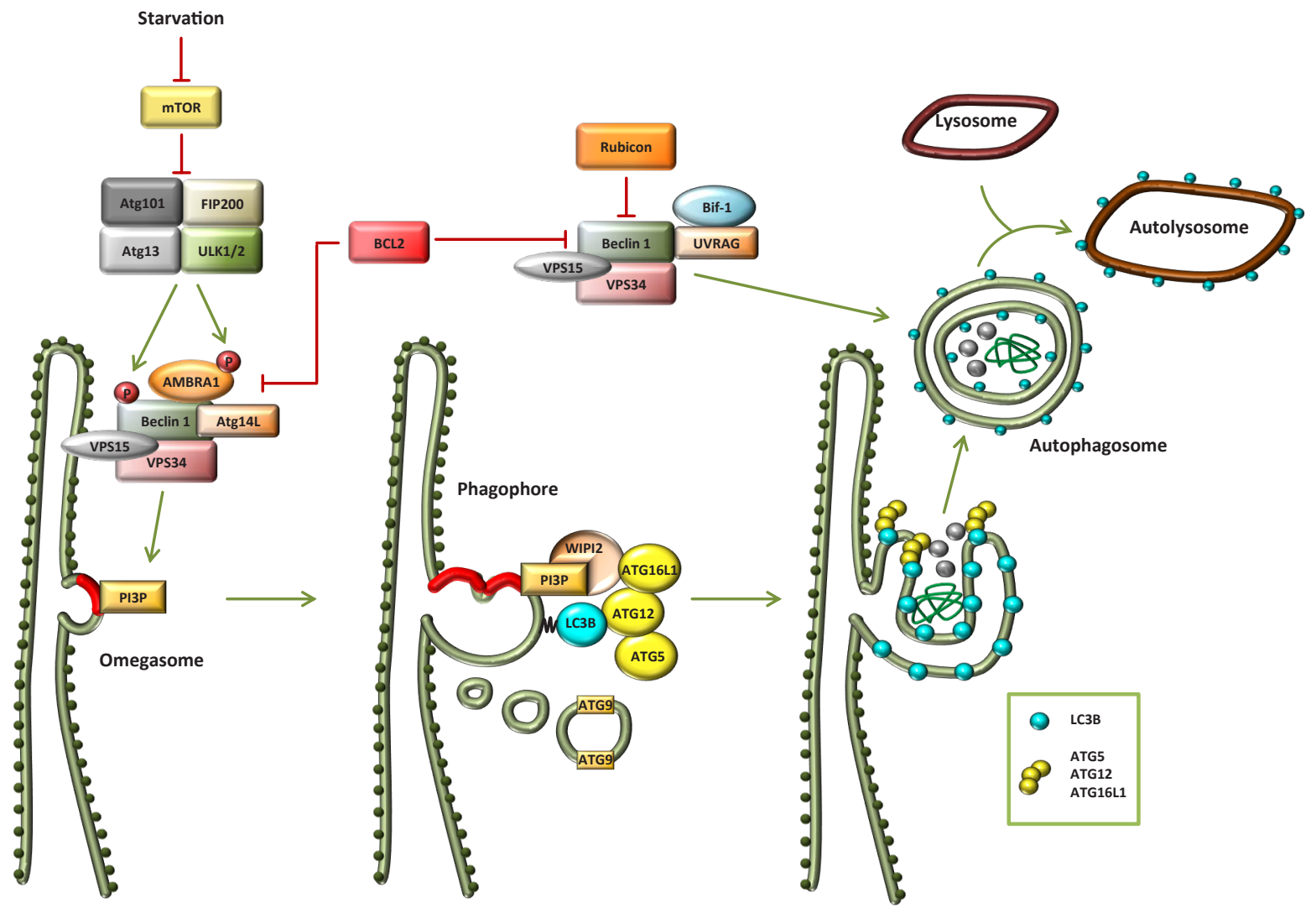

Fig. 1. The autophagy process. Autophagy is negatively regulated by mTOR, a serine/threonine kinase. Upon autophagy induction (e.g. starvation) mTOR is inhibited and promotes ULK complex (Atg101, Atg13, FIP200 and ULK1/2) activation. ULK1 phosphorylates BECLIN 1 and AMBRA1 and stimulates the lipid kinase activity of a first BECLIN 1 complex, composed by BECLIN 1 itself, Vps15, Vps34, Atg14L, AMBRA1 and inhibited by Bcl-2. This complex is responsible for the production of phosphatidylinositol 3-phosphate (PI3P) by the Class III PI 3-kinase, Vps34. PI3P allows the nucleation of an isolation membrane, named omegasome, that curves in the middle forming the phagophore. Here, WIPI-2 binds PI3P on forming vesicles and ATG16L 1, thus allowing the recruitment of both ATG12-5-16L 1 complex and LC3, two E3-like ligases necessary for phagophore elongation and cargo recruitment. Then, phagophore closes to form a double-membrane vesicle, named autophagosome. The complete maturation of autophagosome required the activity of a second Beclin 1 complex, composed by BECLIN 1 itself, Vps15, Vps34, UVRAG, Bif-1 and negatively regulated by both Rubicon and Bcl-2. Finally, autophagosome slides along cytoskeletal structures and fuses with lysosomes forming a large and single vesicle, named autolysosome, where sequestered materials are degraded. 
(MAP1LC3B, best known as LC3) and the LC3-like proteins GATE16 (GABA(A) receptor-associated protein-like 2) and GABARAP ( $\gamma$-aminobutyric acid, GABA receptor-associated protein), which are the mammalian ortholog of yeast Atg8. LC3 is cleaved by Atg4, activated by Atg7, transferred to Atg3 and finally lipidated by the addition of phosphatidylethanolamine (PE) which is mediated by the Atg12-Atg5-Atg16L1 complex (Hanada et al., 2007). Once lipidated, LC3 localizes to the pre-autophagosomes allowing tethering and hemifusion of membranes, which are necessary for autophagosome expansion and closure (Tanida et al., 2004).

General and tissue-specific ATG knockout mice pointed out the essential role of autophagy in early and late steps of development. Autophagy was shown to be induced by a rise of $\mathrm{Ca}^{2+}$ after oocyte fertilization, where maternal ATG proteins allow the degradation of maternal mRNA, proteins and organelles to sustain the early stage proliferation (Tsukamoto et al., 2008; Wada and Sun-Wada, 2014). In addition, autophagy is also responsible for the selective degradation of the paternal mitochondria entered with the spermatozoa (Sato and Sato, 2011). Besides the post-fertilization steps described above, Atg3, Atg5, Atg7 and Atg16L1 genes appear not to be essential for embryogenesis, since their knockout embryos properly complete the development, but die postnatal, since autophagy plays an undisputed role for the survival of animals before breastfeeding care (Komatsu et al., 2005; Kuma et al., 2004; Saitoh et al., 2008; Saitoh and Fujita, 2009; Sou et al., 2008). Conversely, LC3, GABARAP, Atg 4b and Atg4c mutant mice develop normally and also survive after birth, probably because of the presence of multiple Atg 4 and LC3 paralogues in mammals (Cann et al., 2008; Mariño et al., 2010; O'Sullivan et al., 2005; Read et al., 2011). It was also described that Atg5/Atg7 deleted mice form autophagosomes and amphisomes without LC3 lipidation; this Atg5-independent autophagy was detected in several embryonic tissues, playing a relevant role in clearing mitochondria during erythroid maturation (Nishida et al., 2009). In the light of these findings, it remains to clarify whether non-canonical forms of autophagy may compensate the inactivation of the LC3 pathway.

\section{ULK complex and embryogenesis}

ATG1 is a protein kinase identified in yeast as the upstream regulator of the autophagy pathway. ULK1 is the ATG1 ortholog in higher eukaryotes, with five different paralogs in mammalian cells, ULK1-4 and STK36 (Serine/Threonine Kinase 36), of which ULK1 and ULK2 have been shown to regulate autophagy. ATG1/ ULK acts in complex with other autophagy proteins, including ATG13, ATG17/ FIP200 (RB1-inducible coiled-coil 1, RB1CC1) and ATG101 (Fig. 1) (Wong et al., 2013).

The activation of ULK complex is a key event for the initiation of the autophagy cascade. ULK1 phosphorylates BECLIN 1 (Russell et al., 2013) and its partner AMBRA1 (Di Bartolomeo and Corazzari, 2010; Fimia et al., 2007) to activate the BECLIN 1/VPS34 lipid kinase activity and promote autophagosomes nucleation. In addition, ULK complex plays a direct role in the elongation step of autophagosome formation by directly interacting with ATG16L1 (Gammoh and Florey, 2013) and by phosphorylating Folliculin (FLCN), a protein associated with the autophagosomal membrane factor GABARAP (Dunlop et al., 2014; Okazaki et al., 2000).

ULK complex activity is strictly regulated by the energy state of the cell via two main nutrient sensors, mTORC1 (mechanistic target of rapamycin complex 1), and AMPK (AMP-activated protein kinase) (Dunlop and Tee, 2013). Under nutrient-rich conditions, mTOR phosphorylates and inhibits components of the ULK 1 kinase complex, thus preventing autophagy induction (Alers and Löffler, 2012; Hosokawa et al., 2009; Jung et al., 2009). Instead, energy deprivation triggers AMPK that promotes ULK1 kinase activity directly and/or via mTOR inhibition (Kim et al., 2011).

Inactivation of ULK1 ortholog both in C. elegans (unc-51) and $D$. melanogaster (dATG1) causes severe defects in neuronal development causing lethality (Levine and Klionsky, 2004; Meléndez et al., 2003; Toda et al., 2008). In mice, the ulk1-/- and ulk2-/- single knockout mice are born viable (Alers and Löffler, 2012); on the other hand, ulk1,ulk2-/- double mutant leads to pups death 24 hours after birth, due, in this case, to a respiratory distress caused by a reduced autophagy in lung epithelial cells (Cheong et al., 2011; Cheong et al., 2013). Interestingly, the knockout of the ULK1 interactor FIP200 causes embryonic lethality at mid/late gestation associated with defective heart and liver development (Gan et al., 2006) suggesting that in ulk $1 / 2 \mathrm{KOs}$ the other family genes may compensate for their function. This phenotype was initially related to a reduced S6 kinase activation and increased cell death; later, the analysis of mutant mouse embryonic fibroblasts (MEFs) showed that FIP200 is essential for ULK-regulated autophagy (Hara et al., 2008). In addition to its role in autophagy, ULK complex was described to participate to axonal elongation and vesicular transport both in C. elegans (unc-51) and D. melanogaster (dATG1) orthologs (Wong et al., 2013) Similarly, ULK complex of M. musculus was described to orchestrate the development of axons by regulating Rab5-dependent endocytic pathways and Ras-like signaling (Tomoda et al., 2004). Moreover, murine Ulk1 and Ulk2 were found involved in a non-clathrin-coated vesicle endocytosis to regulate NGF (nerve growth factor) internalization in sensory neurons. In response to tropomyosin receptor kinase $A(\operatorname{TrKA})$ activation, ULK1 is poly-K63 ubiquitinated by TNF receptor-associated factor 6 (TRAF6), similar to what described in autophagy, thus promoting the interaction with sequestosome 1 (SQSTM1, best known as p62) and the receptor internalization (Zhou et al., 2011). These observations therefore suggest that, at least in neuronal cells, the activity of ULK complex acts at the crossroad between autophagy, endocytosis and vesicles trafficking (Lamb et al., 2013).

\section{BECLIN1 and embryogenesis}

BECLIN 1 regulates autophagosome formation by interacting with the class III phosphatidylinositol-3-kinase VPS34 to allow the formation of phosphatidylinositol-3 phosphate (PI3P) in various membrane districts (Funderburk et al., 2010). PI3P allows the nucleation of membranous structure, named omegasome (Axe et al., 2008; Petiot and Ogier-Denis, 2000) that curves and acts as a platform for the recruitment of the autophagosome elongation machinery through WIPI-2, a PI3P-associated protein (Dooley et al., 2014). The core of BECLIN 1/VPS34 complex consists of BECLIN 1, VPS34 and its regulatory cofactor VPS15 (phosphoinositide3-kinase, regulatory subunit 4, PI3KR4) (Itakura et al., 2008; Kihara et al., 2001; Liang et al., 2008). The core associates to different proteins forming two distinct complexes that have been described from yeast to mammals. The first one contains Atg14Land is involved in autophagosomes formation, while the second one is associated to UV radiation resistance associated (UVRAG) and acts both in 
autophagosome and endosome maturation (Wirawan etal., 2012). An increasing number of BECLIN 1 interacting proteins, including BCL2 (B-cell CLL/lymphoma 2), Bcl-xL (BCL2-like 1, BCL2L1), Bif1 (SH3-domain GRB2-like endophilin B1, SH3GLB1), AMBRA1, RUBICON (Beclin-1 Associated RUN Domain Containing Protein, KIAA0226) and WASH (WAS protein family homolog) have been described to stimulate or inhibit the kinase activity of VPS34 and, consequently, autophagy (Fimia et al., 2007; Pattingre et al., 2005; Takahashi et al., 2007; Zhong et al., 2009) (Fig. 1). In addition, BECLIN 1 complex is highly regulated at post-translational level by phosphorylation and ubiquitination. It has been shown that stressactivated kinases, such as death-associated protein kinase (DAPK) and c-Jun N-terminal kinases (JNK1), activate BECLIN 1 preventing the inhibitory interaction with Bcl-xL and Bcl-2 (Wei et al., 2008; Zalckvar et al., 2009). Moreover, growth-factors inhibit autophagy by promoting AKT-mediated phosphorylation of BECLIN 1 (Wang et al., 2012; Wei et al., 2013). BECLIN 1 has been shown to be modified by TRAF6 via K63-chain polyubiquitination in response to Toll-like receptors (TLRs) stimulation, interferon gamma (IFN $\gamma$ ) and interleukin 1 (IL-1), as well as to nutrient starvation. Ubiquitination activates BECLIN-1 by promoting its self-association, whereas the deubiquitinating enzyme A20 (TNF alpha-induced protein 3, TNFAIP3) turns off BECLIN 1 by blocking this modification (Shi and Kehrl, 2010). Interestingly, deubiquitinating enzymes ubiquitin specific peptidase 10 (USP10) and USP13 targeting K48-chain polyubiquitination positively regulate BECLIN 1 by ensuring its protein stability (Liu et al., 2011).

Differently from Ulk1, Atg3, Atg5, Atg7 and Atg16L1 knockout mice, the inactivation of autophagy initiation machinery of beclin 1 - , Vps34 - mutant mice results in early embryonic lethality at stages E7.5 and E8.5 respectively (Yue et al., 2003; Zhou et al., 2011). beclin $1^{-/}$mice show a severe developmental delay culminating in a reduced size, that causes embryonic lethality associated with a defective autophagy. Analysis of beclin $1 \%$ stem cells, derived from embryo inner-mass, reveals the inability of embryoid bodies to expand due to an extensive cell death (Yue et al., 2003). Vps34 mutant embryos show defects in mesoderm formation associated with reduced cell proliferation, as shown by the inability to form colonies by the inner-mass (Zhou et al., 2011). The pivotal role of BECLIN 1/VPS34 complex during development is also supported by analysis in other organisms. Indeed, mutations of BECLIN 1 and VPS34 are lethal at the larval stage both in $C$. elegans and D. melanogaster (Juhász et al., 2008; Roggo et al., 2002; Scott et al., 2004; Takacs-Vellai et al., 2005). Recently, BECLIN 1 has been described to bind WASH, a protein involved in the regulation of both endosomal trafficking and autophagy. Mutation of WASH gene in mice results in abnormal embryos with disarrange layers and cavities at the E7.5 that culminate with embryonic lethality at E9.5 (Xia et al., 2013) similar to what observed in beclin 1 and Vps34 mutant mice (Yue et al., 2003; Zhou et al., 2011). WASH ${ }^{-/}$embryos display an excessive rate of cell death associated to massive autophagosome accumulation. How WASH regulates autophagy remains controversial. On the one hand, WASH was reported to be essential for autophagosome formation by binding to VPS35 (Vacuolar Protein Sorting 35 Homolog S. Cerevisiae). VPS35 is a subunit of the retromer complex that mediates retrograde transport from endosomes to trans-Golgi and a D620N mutation of VPS35, which is linked to an autosomal-dominant form of Parkinson's, associates poorly with WASH (Zavodszky and Seaman, 2014).
On the other hand, WASH was shown to inhibit the K63-chain polyubiquitination of BECLIN 1, a modification required for the stimulation of VPS34 activity (Xia et al., 2013). The function of BECLIN 1 related to autophagosome maturation does not appear to be relevant in terms of development, since UVRAG mutant mice are viable and fertile (Song et al., 2014).

BECLIN 1 function in membrane dynamics is not be restricted to autophagy, taking also part to both endocytosis and phagocytosis. For instance, BECLIN 1 complex mediates the internalization and the degradation of the epidermal growth factor receptor also in cells were autophagy was inhibited by knocking down Atg14L, indicating that this is an autophagy-independent function of BECLIN 1 (Thoresen and Pedersen, 2010). Moreover, the activation of TLR signaling by cell corpses in macrophages causes a rapid translocation of BECLIN 1 to phagosomes, which mediates the translocation of LC3 to ensure the fusion with lysosomes (LC3-associated phagocytosis, LAP) (Martinez and Almendinger, 2011; Sanjuan et al., 2007). Consistently, BECLIN 1 was described essential to generate engulfment signals for the phagocytosis of dying cells during development (Qu et al., 2007).

Tumorigenesis is another important process controlled by BECLIN 1. In fact, BECLIN 1 haploinsufficiency leads to uncontrolled proliferation and spontaneous tumor development in many organs (Liang et al., 1999; Qu et al., 2003; Thoresen and Pedersen, 2010).

Although many aspects of the function of BECLIN 1 in embryogenesis remain to be elucidated, it appears evident that its crucial role is linked to its ability to interconnect multiple vesicle trafficking processes.

\section{AMBRA 1 and embryogenesis}

AMBRA1 is a WD40-containing protein conserved among vertebrates. The molecular mechanism by which AMBRA1 regulates autophagy induction has been in-depth analyse in the last years. AMBRA1 binds to BECLIN 1 and positively regulates the lipid kinase activity of BECLIN 1/VPS34 complex, thus promoting autophagosome formation (Fimia et al., 2007; Gu et al., 2014) (Fig. 2). Under unstressed conditions, AMBRA1 activity is inhibited by multiple mechanism, including the mTOR-mediate phosphorylation on Ser52 (Nazio et al., 2013) and its sequestration to microtubules through the interaction with the dynein complex (Di Bartolomeo and Corazzari, 2010), ensuring a reduce autophagy initiation. The activation of the autophagic cascade allows the release of AMBRA1 from dynein complex through ULK1-dependent phosphorylation. AMBRA1 is thus able to translocate to the ER together with BECLIN 1/ VPS34 complex where it promotes autophagosomes nucleation (Di Bartolomeo and Corazzari, 2010) (Fig. 2). Moreover, AMBRA1 regulates autophagy by potentiating the kinase activity and the stability of ULK1 complex (Nazio et al., 2013; Nazio and Cecconi, 2013). Nazio et al., described that, consequent to autophagy activation, AMBRA1 binds the E3-ubiquitin ligase TRAF6 and mediates K63-chain polyubiquitination of ULK1. This event allows ULK1 self-association and stabilization, resulting in an increased kinase activity of the ULK1 complex.

Another level of autophagy regulation by AMBRA1 has been recently identified. AMBRA1 appears to be also important in the temporal regulation of the autophagy response through the dynamic interactions with different Cullin-RING E3 ubiquitin ligases (Antonioli et al., 2014). In non-autophagic conditions, AMBRA1 is 
ubiquitinated by the Cullin 4-DDB1 (damage-specific DNA binding protein 1) E3-ligase complex, which leads to its proteasomal degradation. Autophagic stimulation rapidly promotes AMBRA1 dissociation from Cullin4-DDB1 and consequent protein stabilization. Free from Cullin4, AMBRA1 was shown to interact and inhibit a different Cullin complex, Cullin 5, by binding to the adaptor protein, Elongin $B$. This inhibition allows the stabilization of DEPTOR (DEP domain containing mTOR-interacting protein), an inhibitor of mTOR that rapidly accumulates in autophagy conditions to guarantee the timely activation of the ULK complex. Prolonged stresses lead Cullin 4-DDB1 to bind back to AMBRA1, which causes its sharp degradation and the termination of autophagy response. Altogether, these observations highlight a novel aspect of the crosstalk between autophagy and the ubiquitin proteasome system, mainly focused on the regulation of autophagy dynamics.
AMBRA1 also plays an important role in the autophagic degradation of mitochondria, a process known as mitophagy. It has been shown that a pool of AMBRA1 resides on mitochondria and associates with $\mathrm{Bcl}-2$ in basal conditions, thus preventing the binding of AMBRA 1 to BECLIN 1 and autophagosome formation (Strappazzon and Vietri-Rudan, 2011). Upon mitophagy induction, AMBRA1 dissociates from $\mathrm{Bcl}-2$ and increases its interaction with BECLIN 1 and the E3 ubiquitin ligase PARKIN (RBR E3 ubiquitin protein ligase, PARK2), being able to induce both PARKIN-dependent and -independent mitochondrial clearance (Van Humbeeck et al., 2011; Strappazzon and Nazio, 2014). Moreover, these studies have revealed the capability of AMBRA1 to directly interact with LC3 through an LC3-interacting region (LIR) domain, which contributes to the engulfment of damaged mitochondria within the autophagosomes (Fig. 2).

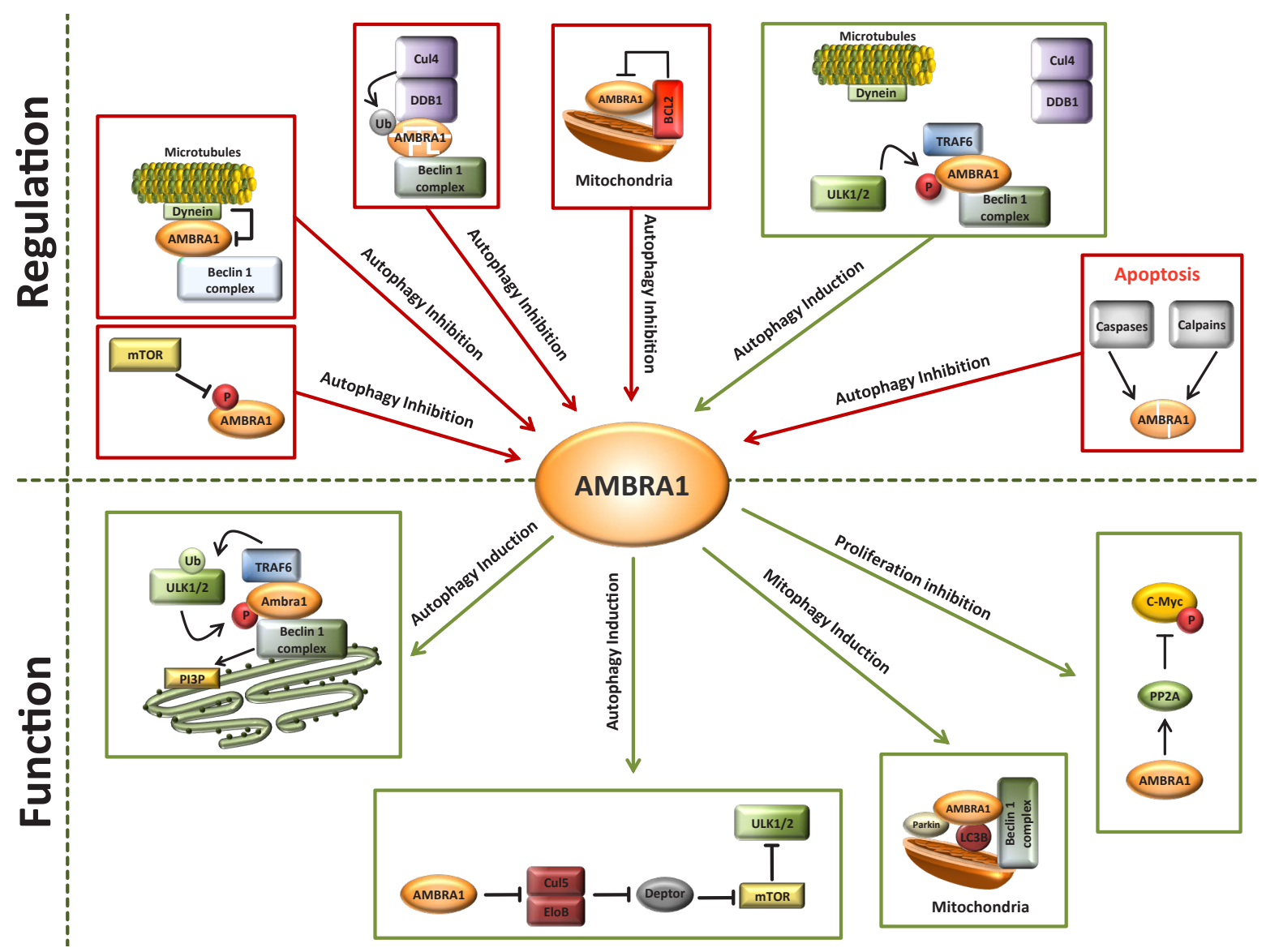

Fig. 2. Regulation of AMBRA1 and its function during autophagy induction. On one hand, AMBRA1 is regulated by different molecules: under unstressful conditions, a) AMBRA1 is inhibited by mTOR phosphorylation on S52 and by its recruitment, together with BECLIN 1 complex, on microtubules through its association with dynein-complex b) a pool of AMBRA1 is ubiquitinated by Cul4-DDB1 E3-ligase complex for proteasomal degradation, thus limiting autophagy induction c) a pool of AMBRA1 is localized to mitochondrial outer membrane where associates with Bcl-2, contributing to mitophagy inhibition. d) Upon autophagy induction, ULK1-dependent phosphorylation of AMBRA1 allows its dissociation from both microtubules and Cul4-DDB1 E3-ligase complex, thus causing AMBRA1 re-localization upon ER and stabilization respectively. e) In addition, AMBRA1 is regulated by apoptosis induction, which causes AMBRA1 degradation through caspase- and calpain-activity and dismantles the autophagy machinery. On the other hands, AMBRA1 regulates a variety of substrates during autophagy induction. f) AMBRA1 binds to BECLIN 1 and positively regulates the lipid kinase activity of BECLIN 1NPS34 complex, and regulates the activity and stability of ULK1 through TRAF6 interaction. g) AMBRA1 inhibits the activity of Cullin 5/EloB E3 ubiquitin ligase complex, thus allowing the stabilization of the mTOR inhibitor Deptor and, consequently the activation of ULK1. h) Upon mitophagy induction, AMBRA1/ BCl-2 interaction is disrupted and AMBRA1 binds with BECLIN 1, PARKIN and LC3, through a LIR domain, inducing both the PARKIN-dependent and -independent mitochondrial clearance. i) Finally, AMBRA1 promotes the phosphatase activity of PP2A on c-Myc, promoting c-Myc dephosphorylation and degradation, and thereby reducing the cell division rate. 
AMBRA1 is a gene crucial for the development of central nervous system (CNS). Initially, AMBRA1 is expressed in the neural plate during the first stages of neurulation, while it becomes ubiquitously expressed at the late stages of embryogenesis and in adult mice (Fimia et al., 2007). Ambra 1 mutant mice show impaired autophagy, accumulation of ubiquitinated protein, unbalanced cellular proliferation and excessive apoptotic cell death, which cause exencephaly and spina bifida and embryonic lethality between E10.5 and E13.5 (Cecconi and Levine, 2008; Fimia et al., 2007). Similarly, inhibition of the paralogous genes ambra $1 a$ and ambra1bin Danio rerioleads to an incomplete development associated to severe embryonic malformations. Two days post-fertilization (dpf) both morphants present an extensive hydrocephalus of midbrain and hindbrain ventricles that produces abnormal head and smaller eyes. At 3 $\mathrm{dpf}$, the phenotype is further exacerbated, culminating in cardiac edema and embryos death in ambra 1 a knockdown animals, and at $4 \mathrm{dpf}$ in case of ambra1b (Benato et al., 2013). Moreover, D. rerio mutated embryos show a lower autophagic activity and increased cell death compare to WT, features similar to Ambra1 mice mutant that further emphasize the functional balance between autophagy and apoptosis during embryogenesis. The functional link of AMBRA1 with apoptosis has been further characterized in in vitro studies. Downregulation of AMBRA1 expression in a variety of cell lines lead to increased susceptibility to different apoptotic stimuli. Moreover, apoptosis induction causes AMBRA1 degradation that occurs in a caspase- and calpain-dependent manner. AMBRA1 cleavage occurs early during the apoptotic process and was observed to precede the decline of other autophagic proteins (Corazzari et al., 2012; Pagliarini et al., 2012).

Many of AMBRA1 binding proteins appear to play a role during development. Traf6 ${ }^{\star}$ mice are viable and appear normal at birth, but they fail to thrive normally and dying prematurely through dysfunctional lymph node organogenesis and IL-1 and lipopolysaccharide (LPS) signaling (Lomaga et al., 1999). Interestingly, Traf6 null mice also show an increase frequency of neural tube closure failure and exencephaly at stage E13.5, that may cause embryonic death depending on the genetic background; this phenotype is associated to deregulated cell death within specific regions of the developing CNS (Lomaga et al., 2000). Cullin 4a knock out mice, with a deletion in the exon 1, was reported to die early during embryogenesis (Li et al., 2002). However, subsequent studies have shown that deletions of different exons of Cul4a do not cause developmental abnormalities, because the previous removal of exon 1 also inadvertently deleted Pcid2 gene on the complementary strand (Kopanja et al., 2011; Liu et al., 2009). On the other hand, Cul $4 b$ null mice show decreased proliferation and increased apoptosis causing embryonic lethality (Jiang et al., 2012), thus indicating that Cul4 gene diverged from Cul4a to carry out some unique functions during embryogenesis. Interestingly, mutations in human CUL4B have been reported as one of the major causes of X-linked mental retardation (Zhou et al., 2007) and the conditional inactivation of DDB1, the substrate adaptor of Cullin 4 complexes, in brain led to neuronal degeneration, brain haemorrhages and neonatal death (Cang et al., 2006). Of note, also Cullin 5 plays a role in the development of cortical development regulating neuron positioning trough DAB1 (Dab, reelin signal transducer, homolog 1) modulation, a protein that directs the migration of neurons during brain development (Feng et al., 2007). Altogether, these observations suggest that a functional relation between AMBRA1 and its associated E3 ubiquitin ligases exists in developing brain.

It has been recently reported that the functions of AMBRA1 in CNS are maintained also in adult mice. Indeed, in neuronal stem cells located in the subventicular zone of lateral ventricles, AMBRA1 and BECLIN 1 are required to promote autophagy during neurogenesis of adult mice (Yazdankhah and Farioli-Vecchioli, 2014). Moreover, the analysis of the AMBRA1 protein levels in adult mice brain revealed that it is widely expressed in the cytosol of pyramidal neurons within the neocortex and hippocampus, and of Purkinje cells in the cerebellar cortex (Sepe et al., 2014). Interestingly, during brain aging, AMBRA1 levels decrease progressively in the neocortex and hippocampus, and a further reduction was observed in Alzheimer's diseases model mice (Tg2576) according to the involvement of autophagy defects in neurodegeneration (Sepe et al., 2014). In line, Ambra1 heterozygous mutant mice present a reduced autophagy in the Schwann cells after nerve injury, which correlates with a persistent neuropathic pain and axonal degeneration in the peripheral nerves (Marinelli et al., 2014). Moreover, significant associations between AMBRA1 and the development of mental disorders were found both in mice and human. It has been reported that AMBRA1 heterozygous female mice present an autism-like behaviour (Dere et al., 2014) and that a human intronic variant of AMBRA1 (rs11819869) is associated to impulsivity-related traits linked to schizophrenia (Heinrich and Nees, 2013). Altogether, these evidences point to an important role of AMBRA1 in maintaining a proper functionality of the central nervous system from embryogenesis to adulthood. The complexity of the phenotypes observed also suggests that for a full understanding of the function of AMBRA1 in the nervous system it will be valuable the availability of conditional Ambra1 KO mice.

Besides its role in the development of nervous systems, AMBRA1 was also observed to play a role in the development of skeletal muscle both in mice and Zebrafish. In both animal models, the reduction of AMBRA1 expression leads to abnormal muscle morphology associated with structural and functional defects of myofiber and disorganization of sarcomeres (Skobo et al., 2014). These defects are associated to a significant alteration of muscular mitochondria morphology, which well correlates with the role of AMBRA1 in the autophagic degradation of mitochondria.

As described above, an important feature of AMBRA1 deficiency, both in vitro and in vivo, is hyperproliferation (Di Bartolomeo and Corazzari, 2010; Fimia et al., 2007). Recently, Cianfanelli et al., have provided clues on how AMBRA1 regulates cell proliferation. AMBRA1 was shown to negatively regulate the activity of the oncogene c-Myc ( $\mathrm{v}$-myc avian myelocytomatosis viral oncogene homolog). This function is mediated by the interaction with the phosphatase acivity of PP2A (serine/threonine protein phosphatase 2A) that promotes c-MycS62 dephosphorylation and protein destabilization (Cianfanelli et al., 2014).

It will be important to establish whether the ability of other component of BECLIN 1 complex to regulate proliferation, e.g. BECLIN 1, Bif-1 and UVRAG (Cianfanelli et al., 2014; Liang et al., 2006; Takahashi et al., 2013; Yue et al., 2003), depend on the PP2A-AMBRA1 interaction.

\section{Conclusion and perspectives}

Several studies in different model organisms have shown that the inhibition of autophagy genes has a significant different impact 
on development. Conclusive explanations for these dissimilarities have not been provided so far. The simple interpretation could be that specific autophagy genes play also a role in other vesicle trafficking processes, such as endocytosis and phagocytosis, or in the control of proliferation. However, it remains conceivable that genes like ULK1, BECLIN 1, and AMBRA1 may also regulate noncanonical forms of autophagy not requiring LC3 family proteins. The evolution of these alternative "autophagies" could be explained by the requirement during development of sustaining the profound modifications in cell architecture by providing a rapid renovation of intracellular components. The detailed characterization of the targets of lysosomal degradation at different stages of embryogenesis is likely to contribute to explain this enigma in the near future.

\section{Acknowledgements}

This work was supported by grants from AIRC (IG2012-13529), the Telethon Foundation (GEP12072), the Italian Ministry of University and Research (FIRB Accordi di Programma 2011) and the Italian Ministry of Health (Ricerca Finalizzata and Ricerca Corrente).

\section{References}

ALERS S, LÖFFLER A (2012). Role of AMPK-mTOR-Ulk1/2 in the regulation of autophagy: cross talk, shortcuts, and feedbacks. Mol Cell Biol 32: 2-11.

ANTONIOLI M, ALBIERO F, NAZIOF (2014). AMBRA1 Interplay with Cullin E3 Ubiquitin Ligases Regulates Autophagy Dynamics. Dev Cell 31: 734-746.

AXE E, WALKER S, MANIFAVAM (2008). Autophagosome formation from membrane compartments enriched in phosphatidylinositol 3-phosphate and dynamically connected to the endoplasmic reticulum. J Cell Biol 182: 685-701.

DI BARTOLOMEO S, CORAZZARI M (2010). The dynamic interaction of AMBRA1 with the dynein motor complex regulates mammalian autophagy. J Cell Biol 191 : 155-168.

BENATO F, SKOBO T, GIOACCHINI G, MORO I, CICCOSANTI F, PIACENTINI M, FIMIA GM, CARNEVALI O, DALLA VALLE L (2013). Ambra1 knockdown in zebrafish leads to incomplete development due to severe defects in organogenesis. Autophagy 9: 476-495.

CANG Y, ZHANG J, NICHOLAS S, BASTIEN J, LI B (2006). Deletion of DDB1 in mouse brain and lens leads to p53-dependent elimination of proliferating cells. Cell 127: 929-940.

CANN GM, GUIGNABERT C, YING L, DESHPANDE N, BEKKER JM, WANG L, ZHOU B, RABINOVITCH M (2008). Developmental expression of LC3alpha and beta: absence of fibronectin or autophagy phenotype in LC3beta knockout mice. Dev Dyn 237: 187-195.

CECCONI F, LEVINE B (2008). The role of autophagy in mammalian development: cell makeover rather than cell death. Dev Cell 15: 344-357.

CHEONG H, LINDSTENT, WU J (2011). Ammonia-induced autophagy is independent of ULK1/ULK2 kinases. Proc Natl Acad Sci USA 108: 11121-11126.

CHEONG H, WU J, GONZALES L (2013). Analysis of a lung defect in autophagydeficient mouse strains. Autophagy 10: 45-56.

CIANFANELLI V, FUOCO C, LORENTE M, SALAZAR M, QUONDAMATTEO F, GHERARDINI PF, DE ZIO D, NAZIO F, ANTONIOLI M, D'ORAZIO M, et al., (2014). AMBRA1 links autophagy to cell proliferation and tumorigenesis by promoting C-Myc dephosphorylation and degradation. Nat Cell Biol 17: 20-30.

CORAZZARI M, FIMIA GM, PIACENTINI M (2012). Dismantling the autophagic arsenal when it is time to die: concerted AMBRA1 degradation by caspases and calpains. Autophagy 8: 1255-1257.

CUERVO AM (2010). Chaperone-mediated autophagy: selectivity pays off. Trends Endocrinol Metab 21: 142-150.

DERE E, DAHM L, LU D (2014). Heterozygous Ambra1 Deficiency in Mice: A Genetic Trait with Autism-Like Behavior Restricted to the Female Gender. Front Behav Neurosci 8: 181.

DOOLEY HC, RAZI M, POLSON HEJ, GIRARDIN SE, WILSON MI, TOOZE SA (2014). WIPI2 links LC3 conjugation with PI3P, autophagosome formation, and pathogen clearance by recruiting Atg12-5-16L1. Mol Cell 55: 238-252.
DUNLOP E, SEIFANS, CLAESSENST (2014). FLCN, a novel autophagy component, interacts with GABARAP and is regulated by ULK1 phosphorylation. Autophagy 10: 1749-1760.

DUNLOP E, TEE A (2013). The kinase triad, AMPK, mTORC1 and ULK1, maintains energy and nutrient homoeostasis. Biochem Soc Trans 41: 939-943.

DUPONT N, CODOGNO P (2013). Non-canonical Autophagy: Facts and Prospects. Curr Pathobiol Rep 1: 263-271.

FENG L, ALLEN N, SIMO S, COOPER J (2007). Cullin 5 regulates Dab1 protein levels and neuron positioning during cortical development. Genes Dev 21: 2717-2730.

FIMIA G, STOYKOVA A, ROMAGNOLI A (2007). Ambra1 regulates autophagy and development of the nervous system. Nature 447: 1121-1125.

FUNDERBURK SF, WANG QJ, YUE Z (2010). The Beclin 1-VPS34 complex--at the crossroads of autophagy and beyond. Trends Cell Biol 20: 355-362.

GAMMOH N, FLOREY O (2013). Interaction between FIP200 and ATG16L1 distinguishes ULK1 complex-dependent and-independent autophagy. Nat Struct Mol Biol 20: 144-149.

GAN B, PENG X, NAGY T, ALCARAZ A (2006). Role of FIP200 in cardiac and liver development and its regulation of TNF $\alpha$ and TSC-mTOR signaling pathways. $J$ Cell Biol 175: 121-133.

GU W, WAN D, QIAN Q, YI B, HE Z, GU Y, WANG L, HE S (2014). Ambra1 is an essential regulator of autophagy and apoptosis in SW620 cells: Pro-survival role of Ambra1. PLoS One 9: e90151.

HANADA T, NODA N, SATOMI Y (2007). The Atg12-Atg5 conjugate has a novel E3like activity for protein lipidation in autophagy. J Biol Chem 282: 37298-37302.

HARAT, TAKAMURAA, KISHIC (2008). FIP200, a ULK-interacting protein, is required for autophagosome formation in mammalian cells. J Cell Biol 181: 497-510.

HEINRICHA, NEESF (2013). From gene to brain to behavior: schizophrenia-associated variation in AMBRA1 alters impulsivity-related traits. EurJ Neurosci38: 2941-2945.

HOSOKAWAN, SASAKIT, IEMURAS (2009). Atg101, a novel mammalian autophagy protein interacting with Atg13. Autophagy 5: 973-979.

HUANG W-P, KLIONSKY DJ (2002). Autophagy in Yeast: A Review of the Molecular Machinery. Cell Struct Funct 27: 409-420.

VAN HUMBEECK C, CORNELISSEN T, VANDENBERGHE W (2011). Ambra1: a Parkin-binding protein involved in mitophagy. Autophagy 7: 1555-1556.

ITAKURA E, KISHI C, INOUE K, MIZUSHIMA N (2008). Beclin 1 forms two distinct phosphatidylinositol 3-kinase complexes with mammalian Atg14 and UVRAG. Mol Biol Cell 19: 5360-5372.

JIANG B, ZHAO W, YUAN J, QIAN Y, SUN W, ZOU Y (2012). Lack of Cul4b, an E3 ubiquitin ligase component, leads to embryonic lethality and abnormal placental development. PLoS One 7: e37070.

JUHÁSZ G, HILL J, YAN Y (2008). The class III PI (3) K Vps34 promotes autophagy and endocytosis but not TOR signaling in Drosophila. J Cell Biol 181: 655-666.

JUNG C, JUN C, RO S (2009). ULK-Atg13-FIP200 complexes mediate mTOR signaling to the autophagy machinery. Mol Biol Cell 20: 1992-2003.

KIHARAA, KABEYA Y, OHSUMIY, YOSHIMORIT (2001). Beclin-phosphatidylinosito 3-kinase complex functions at the trans-Golgi network. EMBO Rep 2: 330-335.

KIM J, KUNDU M, VIOLLETB, GUAN K (2011). AMPK and mTOR regulate autophagy through direct phosphorylation of Ulk1. Nat Cell Biol 13: 132-141.

KIM KH, LEE M-S (2014). Autophagy--a key player in cellular and body metabolism. Nat Rev Endocrinol 10: 322-337.

KLIONSKYDJ, ABDALLAFC, ABELIOVICHH, ABRAHAM RT, ACEVEDO-AROZENA A, ADELI K, AGHOLME L, AGNELLO M, AGOSTINIS P, AGUIRRE-GHISO JA, et al., (2012). Guidelines for the use and interpretation of assays for monitoring autophagy. Autophagy 8: 445-544.

KOMATSU M, WAGURI S, UENO T (2005). Impairment of starvation-induced and constitutive autophagy in Atg7-deficient mice. J Cell Biol 169: 425-434.

KOPANJA D, ROY N, STOYANOVA T, HESS RA, BAGCHI S, RAYCHAUDHURI P (2011). Cul4A is essential for spermatogenesis and male fertility. Dev Biol 352 278-287.

KUMA A, HATANO M, MATSUI M, YAMAMOTO A (2004). The role of autophagy during the early neonatal starvation period. Nature 432: 1032-1036.

LAMB C, DOOLEY H, TOOZE S (2013). Endocytosis and autophagy: shared machinery for degradation. Bioessay 35: 34-45.

LEVINE B, KLIONSKY D (2004). Development by self-digestion: molecular mecha- 
nisms and biological functions of autophagy. Dev Cell 6: 463-477.

LI B, RUIZ J, CHUN K (2002). CUL-4A is critical for early embryonic development. Mol Cell Biol 22: 4997-5005.

LI W, LI J, BAO J (2012). Microautophagy: lesser-known self-eating. Cell Mol Life Sci 69: 1125-1136.

LIANG C, FENG P, KU B, DOTAN I, CANAANI D (2006). Autophagic and tumour suppressor activity of a novel Beclin1-binding protein UVRAG. Nat CellBio/8:688-699.

LIANG C, LEE J, INN K, GACK M, LI Q (2008). Beclin1-binding UVRAG targets the class $C$ Vps complex to coordinate autophagosome maturation and endocytic trafficking. Nat Cell Biol 10: 776-787.

LIANG X, JACKSON S, SEAMAN M, BROWN K (1999). Induction of autophagy and inhibition of tumorigenesis by beclin 1. Nature.

LIU J, XIA H, KIM M, XU L, LI Y, ZHANG L, CAI Y, NORBERG HV, ZHANG T, FURUYA $\mathrm{T}$, et al., (2011). Beclin1 controls the levels of p53 by regulating the deubiquitination activity of USP10 and USP13. Cell 147: 223-234.

LIU L, LEE S, ZHANG J, PETERS S, HANNAH J (2009). CUL4A abrogation augments DNA damage response and protection against skin carcinogenesis. $\mathrm{Mol}$ Cell 34: 451-460.

LOMAGA M a., YEH W-C, SAROSI I, DUNCAN GS, FURLONGER C, HO a., MORONY S, CAPPARELLI C, VAN G, KAUFMAN S, et al., (1999). TRAF6 deficiency results in osteopetrosis and defective interleukin-1, CD40, and LPS signaling. Genes Dev 13: 1015-1024.

LOMAGA MA, HENDERSON JT, ELIA AJ, ROBERTSON J, NOYCE RS, YEH W, MAK TW (2000). Tumor Necrosis Factor Receptor-Associated Factor 6 (TRAF6) Deficiency Results in Exencephaly and Is Required for Apoptosis within the Developing CNS. J Neurosci 20: 7384-7393.

MARINELLI S, NAZIO F, TINARI A, CIARLO L (2014). Schwann cell autophagy counteracts the onset and chronification of neuropathic pain. PAIN 155: 93-107.

MARIÑO G, FERNÁNDEZ AF, CABRERA S, LUNDBERG YW, CABANILLAS R, RODRÍGUEZ F, SALVADOR-MONTOLIU N, VEGA JA, GERMANÀ A, FUEYO A, FREIJE JMP, LÓPEZ-OTÍN C (2010). Autophagy is essential for mouse sense of balance. J Clin Invest 120: 2331-2344.

MARTINEZ J, ALMENDINGER J (2011). Microtubule-associated protein 1 light chain 3 alpha (LC3)-associated phagocytosis is required for the efficient clearance of dead cells. Proc Natl Acad Sci USA 108: 17396-17401.

MELÉNDEZA, TALLÓCZYZ, SEAMAN M (2003). Autophagy genes are essential for dauer development and life-span extension in C. elegans. Science 301:1387-1391.

MIZUSHIMA N, KUMA A (2003). Mouse Apg16L, a novel WD-repeat protein, targets to the autophagic isolation membrane with the Apg12-Apg5 conjugate. J Cell Sci 116(Pt 9): 1679-1688.

MIZUSHIMA N, NODA T, YOSHIMORI T, TANAKA Y (1998). A protein conjugation system essential for autophagy. Nature 395: 395-398.

NAZIO F, CECCONI F (2013). mTOR, AMBRA1, and autophagy: an intricate relationship. Cell Cycle 12: 2524-2525.

NAZIO F, STRAPPAZZON F, ANTONIOLI M (2013). mTOR inhibits autophagy by controlling ULK1 ubiquitylation, self-association and function through AMBRA1 and TRAF6. Nat Cell Biol 15: 406-416.

NISHIDA Y, ARAKAWA S, FUJITANI K, YAMAGUCHI H, MIZUTA T, KANASEKI T, KOMATSU M, OTSU K, TSUJIMOTO Y, SHIMIZU S (2009). Discovery of Atg5/ Atg7-independent alternative macroautophagy. Nature 461: 654-658.

O'SULLIVAN GA, KNEUSSEL M, ELAZAR Z, BETZ H (2005). GABARAP is not essential for GABA receptor targeting to the synapse. Eur J Neurosci22: 2644-2648.

OKAZAKI N, YAN J, YUASA S, UENO T (2000). Interaction of the Unc-51-like kinase and microtubule-associated protein light chain 3 related proteins in the brain: possible role of vesicular transport in axonal. Brain Res Mol Brain Res 85(1-2): 1-12.

PAGLIARINI V, WIRAWAN E, ROMAGNOLI A, CICCOSANTI F, LISI G, LIPPENS S, CECCONI F, FIMIA GM, VANDENABEELE P, CORAZZARI M PM (2012). Proteolysis of Ambra1 during apoptosis has a role in the inhibition of the autophagic pro-survival response. Cell Death Differ 19: 1495-1504.

PARZYCH KR, KLIONSKY DJ (2014). An overview of autophagy: morphology, mechanism, and regulation. Antioxid Redox Signal 20: 460-473.

PATTINGRE S, TASSA A, QU X, GARUTI R (2005). Bcl-2 antiapoptotic proteins inhibit Beclin 1-dependent autophagy. Cell 122: 927-939.

PETIOTA, OGIER-DENISE (2000). Distinct classes of phosphatidylinositol $3^{\prime}$-kinases are involved in signaling pathways that control macroautophagy in HT-29 cells.
J Biol Chem 275: 992-998.

QU X, YU J, BHAGAT G (2003). Promotion of tumorigenesis by heterozygous disruption of the beclin 1 autophagy gene. J Clin Invest 112: 1809-1820.

QUX,ZOUZ, SUNQ, LUBY-PHELPS K (2007). Autophagy gene-dependent clearance of apoptotic cells during embryonic development. Cell 128: 931-946.

READ R, SAVELIEVA K, BAKER K, HANSEN G, VOGEL P (2011). Histopathologi$\mathrm{cal}$ and neurological features of Atg $4 \mathrm{~b}$ knockout mice. Vet Pathol 48: 486-494.

ROGGO L, BERNARD V, KOVACS A (2002). Membrane transport in Caenorhabditis elegans: an essential role for VPS34 at the nuclear membrane. EMBO J 21: 1673-1683.

RUSSELL R, TIAN Y, YUAN H, PARK H (2013). ULK1 induces autophagy by phosphorylating Beclin-1 and activating VPS34 lipid kinase. Nat Cell Biol 15: 741-750.

SAITOH T, FUJITA N (2009). Atg9a controls dsDNA-driven dynamic translocation of STING and the innate immune response. Proc NatlAcad SciUSA 106:20842-20846.

SAITOH T, FUJITA N, JANG MH, UEMATSU S, YANG B-G, SATOH T, OMORI H, NODA T, YAMAMOTO N, KOMATSU M, TANAKA K, KAWAI T, TSUJIMURA T, TAKEUCHI O, YOSHIMORI T, AKIRA S (2008). Loss of the autophagy protein Atg16L1 enhances endotoxin-induced IL-1 beta production. Nature 456: 264-268.

SANJUAN M, DILLON C, TAIT S (2007). Toll-like receptor signalling in macrophages links the autophagy pathway to phagocytosis. Nature 450: 1253-1257.

SATO M, SATOK (2011). Degradation of paternal mitochondria by fertilization-triggered autophagy in C. elegans embryos. Science 334: 1141-1144.

SCHNEIDER JL, CUERVO AM (2014). Autophagy and human disease: emerging themes. Curr Opin Genet Dev 26C: 16-23.

SCOTT R, SCHULDINER O, NEUFELDT (2004). Role and Regulation of StarvationInduced Autophagy in the Drosophila Fat Body. Dev Cell 7: 167-167.

SEPE S, NARDACCIR, FANELLIF, ROSSOP(2014). Expression of Ambra1 in mouse brain during physiological and Alzheimer type aging. Neurobiol Aging 35: 96-108.

SHEN H-M, MIZUSHIMA N (2014). At the end of the autophagic road: an emerging understanding of lysosomal functions in autophagy. Trends Biochem Sci39:61-71.

SHI C, KEHRL J (2010). TRAF6 and A20 regulate lysine 63-linked ubiquitination of Beclin-1 to control TLR4-induced autophagy. Sci Signa/ 3: ra42.

SKOBO T, BENATO F, GRUMATI P (2014). Zebrafish ambra1a and ambra1b Knockdown Impairs Skeletal Muscle Development. PLoS One 9: e99210.

SONG Z, AN L, YE Y, WU J (2014). Essential role for UVRAG in autophagy and maintenance of cardiac function. Cardiovasc Res 101: 48-56.

SOU Y, WAGURI S, IWATA J (2008). The Atg8 conjugation system is indispensable for proper development of autophagic isolation membranes in mice. Mol Biol Cell 19: 4762-4775.

STRAPPAZZON F, NAZIO F (2014). AMBRA1 is able to induce mitophagy via LC3 binding, regardless of PARKIN and p62/SQSTM1. Cell Death Differ 22: 419-432.

STRAPPAZZON F, VIETRI-RUDAN M (2011). Mitochondrial BCL-2 inhibits AMBRA1induced autophagy. EMBO J 30: 1195-1208.

TAKACS-VELLAI K, VELLAI T, PUOTI A, PASSANNANTE M, WICKY C, STREIT A KOVACS AL, MÜLLERF (2005). Inactivation of the autophagy gene bec- 1 triggers apoptotic cell death in C. elegans. Curr Biol 15: 1513-1517.

TAKAHASHI Y, COPPOLA D, MATSUSHITA N (2007). Bif-1 interacts with Beclin 1 through UVRAG and regulates autophagy and tumorigenesis. Nat Cell Biol 9 : 1142-1151.

TAKAHASHI Y, HORI T, COOPER T (2013). Bif-1 haploinsufficiency promotes chromosomal instability and accelerates Myc-driven lymphomagenesis via suppression of mitophagy. Blood 121: 1622-1632.

TANIDA I, UENO T, KOMINAMI E (2004). LC3 conjugation system in mammalian autophagy. Int J Biochem Cell Biol 36: 2503-2518.

THORESEN S, PEDERSEN N (2010). A phosphatidylinositol 3-kinase class III sub-complex containing VPS15, VPS34, Beclin 1, UVRAG and BIF-1 regulates cytokinesis and degradative endocytic traffic. Exp Cell Res 316: 3368-3378.

TODA H, MOCHIZUKI H, FLORES R (2008). UNC-51/ATG1 kinase regulates axonal transport by mediating motor-cargo assembly. Genes Dev 22: 3292-3307.

TOMODA T, KIM J, ZHAN C, HATTEN M (2004). Role of Unc51. 1 and its binding partners in CNS axon outgrowth. Genes Dev 18: 541-558.

TSUKAMOTO S, KUMA A, MURAKAMI M (2008). Autophagy is essential for preimplantation development of mouse embryos. Science 321: 117-120. 
WADA Y, SUN-WADA G-H, KAWAMURA N, AOYAMA M (2014). Role of autophagy in embryogenesis. Curr Opin Genet Dev 27: 60-66.

WANG R, WEI Y, AN Z, ZOU Z, XIAO G (2012). Akt-mediated regulation of autophagy and tumorigenesis through Beclin 1 phosphorylation. Science 338: 956-959.

WEI Y, PATTINGRE S, SINHAS, BASSIK M, LEVINE B (2008). JNK1-mediated phosphorylation of $\mathrm{Bcl}-2$ regulates starvation-induced autophagy. Mol Cell30:678-688.

WEI Y, ZOU Z, BECKER N, ANDERSON M (2013). EGFR-mediated Beclin 1 phosphorylation in autophagy suppression, tumor progression, and tumor chemoresistance. Cell 154: 1269-1284.

WIRAWAN E, LIPPENS S, VANDEN BERGHE T, ROMAGNOLI A, FIMIA GM, PIACENTINI M, VANDENABEELE P (2012). Beclin1: a role in membrane dynamics and beyond. Autophagy 8: 6-17.

WONG P, PUENTE C, GANLEY I, JIANG X (2013). The ULK1 complex: sensing nutrient signals for autophagy activation. Autophagy 9: 124-137.

XIA P, WANG S, DU Y, ZHAO Z, SHI L (2013). WASH inhibits autophagy through suppression of Beclin 1 ubiquitination. EMBO J 32: 2685-2696.

YAZDANKHAH M, FARIOLI-VECCHIOLIS (2014). The autophagy regulators Ambra1 and Beclin 1 are required for adult neurogenesis in the brain subventricular zone. Cell Death Dis 5:e1403.
YUE Z, JIN S, YANG C (2003). Beclin 1, an autophagy gene essential for early embryonic development, is a haploinsufficient tumor suppressor. Proc Natl Acad Sci USA 100: 15077-15082.

ZALCKVAR E, BERISSI H, MIZRACHY L, IDELCHUK Y, KOREN I, EISENSTEIN M SABANAY H, PINKAS-KRAMARSKI R, KIMCHI A (2009). DAP-kinase-mediated phosphorylation on the $\mathrm{BH} 3$ domain of beclin 1 promotes dissociation of beclin 1 from $\mathrm{Bcl}-\mathrm{XL}$ and induction of autophagy. EMBO Rep 10: 285-292.

ZAVODSZKY E, SEAMAN M (2014). Mutation in VPS35 associated with Parkinson's disease impairs WASH complex association and inhibits autophagy. Nat Commun. 5: 3828 .

ZHONG Y, WANG Q, LI X, YAN Y (2009). Distinct regulation of autophagic activity by Atg14L and Rubicon associated with Beclin 1-phosphatidylinositol-3-kinase complex. Nat Cell Biol 11: 468-476.

ZHOU X, BABU J, SILVA S da (2007). Unc-51-like kinase 1/2-mediated endocytic processes regulate filopodia extension and branching of sensory axons. Proc Natl Acad Sci USA 104: 5842-5847.

ZHOU X, TAKATOH J, WANG F (2011). The mammalian class 3 PI3K (PIK3C3) is required for early embryogenesis and cell proliferation. PLoS One 6: e16358. 


\section{Further Related Reading, published previously in the Int. J. Dev. Biol.}

Apoptosis in Drosophila: compensatory proliferation and undead cells Francisco A. Martín, Ainhoa Peréz-Garijo and Ginés Morata Int. J. Dev. Biol. (2009) 53: 1341-1347.

http://dx.doi.org/10.1387/ijdb. 072447fm

Key apoptosis regulating proteins are down-regulated during postnatal tissue development

Shane D. Madden, Maryanne Donovan and Thomas G. Cotter

Int. J. Dev. Biol. (2007) 51: 415-424

http://dx.doi.org/10.1387/ijdb. 062263sm

Regulation of programmed cell death during neural induction in the chick embryo Anna Gibson, Neil Robinson, Andrea Streit, Guojun Sheng and Claudio D. Stern Int. J. Dev. Biol. (2011) 55: 33-43

http://dx.doi.org/10.1387/ijdb. 103233sg

5 yr ISI Impact Factor $(2013)=2.879$
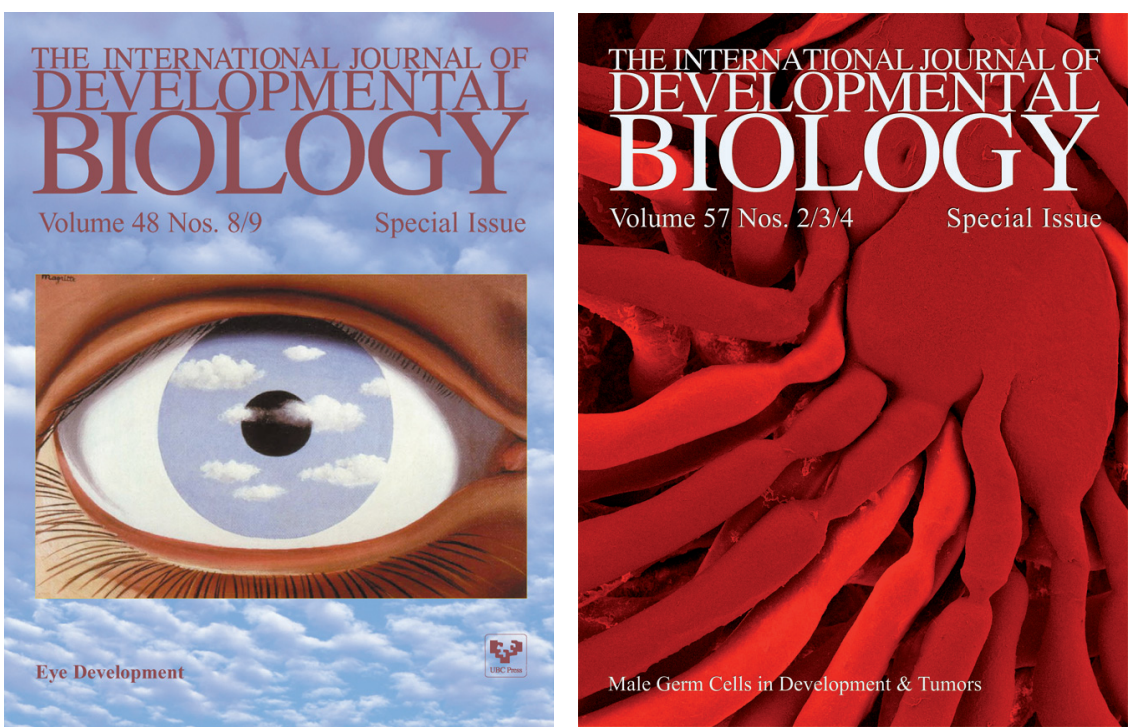
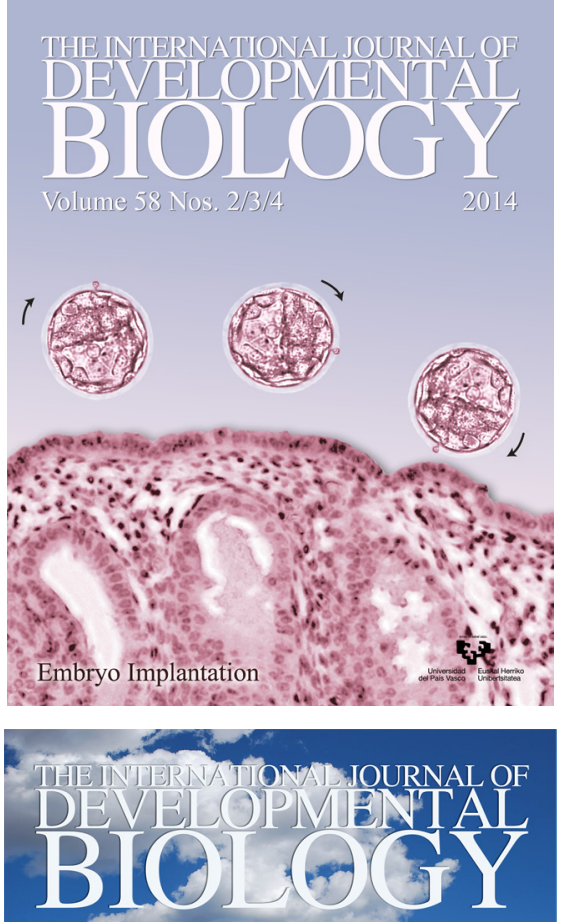

Volume 56 Nos - 10/11/12 - Special Issue

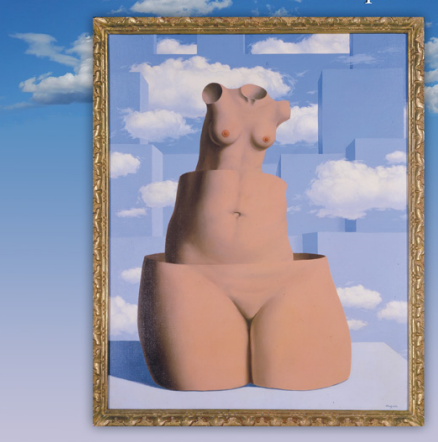

Female Germ Cells in Development \& Tumors 